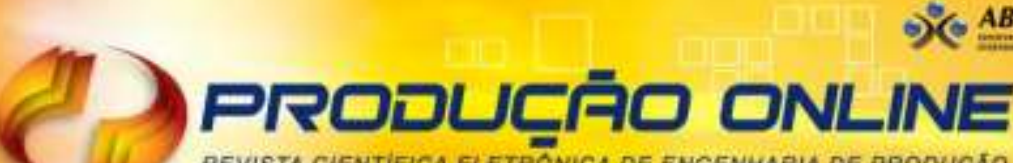 REVISTA CIENTIFICA ELETRONICA DE ENGENHARIA DE PRODUCAO ISSN 1676-1901
}

\section{EXPLORANDO AS CARACTERÍSTICAS DA CAPACIDADE DE INOVAÇÃO DE FIRMAS EM ATIVIDADES PRODUTIVAS DE BAIXA INTENSIDADE TECNOLÓGICA ${ }^{1}$}

\section{EXPLORING INNOVATION CAPABILITIES' CHARACTERISTICS IN LOW-TECH FIRMS}

\author{
Daniele Mello Benedet* E-mail: danielemlbt@hotmail.com \\ Janaina Ruffoni* E-mail: iruffoni@unisinos.br \\ Fernanda Maciel Reichert** E-mail: fernanda.reichert@ufrgs.br \\ *Universidade do Vale do Rio dos Sinos (UNISINOS), São Leopoldo, RS \\ **Universidade Federal do Rio Grande do Sul (UFRGS), Porto Alegre, RS
}

Resumo: $O$ artigo analisa a capacidade de inovação de firmas de baixa intensidade tecnológica, com base no 'Modelo das Capacidade de Inovação'. O Modelo compreende a capacidade de inovação da firma a partir de quatro outras: desenvolvimento, operação, gestão e transação. Para tanto, foi realizada uma pesquisa de campo em duas firmas agroindustriais da região dos Campos de Cima da Serra no Rio Grande do Sul/Brasil. As firmas investigadas apresentaram as quatro capacidades previstas no modelo, sendo que uma delas se destacou em cada firma: a capacidade de transação na primeira empresa e a de operação na segunda. Não houve destaque para a capacidade de desenvolvimento, como previsto para firmas de baixa intensidade tecnológica, mas isso não significa que as firmas não tenham rotinas que envolvam a inovação. Essa visão mais abrangente da capacidade de inovação, proporcionada pelo modelo utilizado, contribui para complementar os estudos sobre a complexa natureza do processo inovativo nas firmas. Os resultados apontam também para a necessidade de repensar alguns aspectos do modelo e aplicá-lo novamente no contexto low-tech.

Palavras-chave: Capacidades de inovação da firma. Empresas de baixa intensidade tecnológica. Agroindústria do RS.

\begin{abstract}
The paper analyzes the innovation capabilities of low technology firms grounded on the "Innovation Capabilities Model". This model divides the innovation capabilities in four: development, operations, management and transaction capability. The empirical analysis is based on two agribusiness firms located in Campos de Cima da Serra in Rio Grande do Sul / South of Brazil. Both firms present the four capabilities of the model, however, one capability is predominant in each firm: transaction and operations. The development capability was not a priority on these firms, as expected in low-technology firms, but it does not mean they do not have innovative routines. This broader approach to innovation, allowed to be captured by the model applied, contributes to complement existing studies on the complex nature of firms' innovative process. The results also point to the necessity to make some reconsiderations about the model and apply it again in the low-tech context.
\end{abstract}

Keywords: Firm's innovation capabilities. Low-technology firms. Agribusiness.

\footnotetext{
${ }^{1}$ Esse artigo é resultado da pesquisa empírica de uma dissertação de mestrado e de discussões teóricas realizadas no âmbito do projeto de pesquisa "Caminhos da Inovação da Indústria Gaúcha" (Edital 08/2009 FAPERGS/CNPq - PRONEX) em que estavam envolvidas as autoras deste trabalho.
} 


\section{INTRODUÇÃO}

Uma preocupação central atualmente das áreas de conhecimento que estudam a competitividade da firma é compreender o seu processo de inovação, visto que a inovação, na forma de progresso tecnológico, é um dos principais elementos para se explicar o dinamismo de funcionamento da economia capitalista. Sendo assim, releva compreender como a firma inova e, para tanto, um elemento central neste processo é a capacidade da firma de gerar o novo, agregar valor, inovar.

Um olhar para a literatura especializada aponta que os estudos a respeito da inovação têm, em geral, focado nas especificidades de setores produtivos, empresas industriais e de serviços ou em produtos de alta tecnologia. No entanto, se a inovação é entendida como um elemento central para a sobrevivência e aumento da competitividade das empresas, entende-se que tal fenômeno mostra-se presente em qualquer setor produtivo, independentemente de ser de alta, média ou de baixa tecnologia ${ }^{2}$ e em firmas de qualquer atividade. A questão que surge, portanto, é: empresas que pertencem a setores de baixa intensidade tecnológica possuem capacidade para inovar? Se positivo, quais são as características da sua capacidade de inovação?

Para avançar, é preciso melhor compreender o que é capacidade de inovação. Interessante observar que a literatura relata que inicialmente a discussão teórica a respeito da capacidade inovativa das empresas teve ênfase em um aspecto específico: a capacidade tecnológica (LALL, 1992; BELL; PAVITT, 1995; KIM, 1999). Essa pressupõe que para inovar, ter foco em atividades tecnológicas de pesquisa e desenvolvimento (P\&D) seria necessário e suficiente. Então, capacidade inovativa e capacidade tecnológica eram compreendidas como sinônimos. Avanços nas discussões teóricas foram apontando limites desta percepção, considerada restrita, e destacando que a capacidade de inovação deve abranger outras especificidades para

\footnotetext{
${ }^{2}$ A Organização para a Cooperação e Desenvolvimento Econômico - OCDE (2011), divide os setores industriais de acordo com o percentual do faturamento que é investido em pesquisa e desenvolvimento (P\&D) por empresas de cada setor. O Joint Research Center of the European Commission, publicou pela OECD (2014) a seguinte divisão: (i) baixa intensidade tecnológica, abaixo de 1,0\% do faturamento é investido nas atividades de P\&D; (ii) media-baixa intensidade, entre 1,0\% e 2,5\%; (iii) media-alta, entre $2,5 \%$ e $7 \%$ e; (iv) alta tecnologia, acima de $7 \%$. Setores como o de alimentos e bebidas, que estão entre os principais elementos do agronegócio, são de baixa intensidade tecnológica segundo essa classificação.
} 
explicar a diferenciação das empresas no mercado, considerando outras atividades (como por exemplo, gestão, comercialização e produção) (GUAN; MA, 2003; YAM et al., 2004; ZAWISLAK et al., 2012). Assim, propõe-se neste artigo, um olhar mais amplo para a capacidade de inovação, incluindo outros elementos além da que a visão tradicional, onde o investimento em P\&D é considerado o principal indicador da atividade de inovação da firma (VON TUNZELMANN; ACHA, 2005; ROBERTSON; SMITH, 2008; HIRSCH-KREINSEN et al., 2008). Entende-se que, da mesma forma que o conceito de inovação foi ganhando amplitude - de inovação tecnológica de forma restrita, para inovação de forma mais ampla (mercadológica, organizacional e outras) -, o conceito de capacidade inovativa também foi ganhando complexidade.

Para responder às perguntas colocadas anteriormente, este artigo apresenta uma discussão a respeito da construção do conceito de capacidade de inovação da firma e ancora-se em uma visão ampla da capacidade de inovação, a partir do uso de um modelo atual de capacidade inovativa da firma (ZAWISLAK et al., 2012; 2013a; 2014). A utilidade deste modelo para o estudo reside no fato de considerar a capacidade de inovação das firmas como resultado de esforços presentes em quatro dimensões da inovação: desenvolvimento, operação, gestão e transação. Por conta disso, entende-se a relevância do modelo escolhido para analisar empresas de setores de baixa intensidade tecnológica, onde, em geral, as atividades inovativas não têm centralidade exclusiva na área tecnológica, mas precisam atingir outras áreas a fim de conferir à firma condições distintas para competir.

A emergência desta discussão é relativamente nova, considerando a conjunção de capacidade inovativa da firma de setores de baixa intensidade tecnológica. Sendo assim, optou-se por uma pesquisa exploraria e pelo método de estudo de caso. Foram analisadas duas empresas do setor do agronegócio da região dos Campos de Cima da Serra do Rio Grande do Sul, que realizaram um processo de mudança tecnológica e agregaram mais valor aos seus produtos e processos produtivos, mostrando realizarem rotinas para a inovação. Desta forma, o objetivo principal do artigo foi analisar as características da capacidade de inovação de duas firmas atuantes em um segmento produtivo considerado de baixa intensidade tecnológica. 
O artigo está organizado em mais quatro seções. A seguir, discute-se a compreensão de capacidade de inovação e apresenta-se o modelo utilizado no estudo. Depois, na terceira seção, apresenta-se o método utilizado, para, em seguida, discorrer sobre os casos estudados. Por fim, apresentam-se as considerações finais do estudo.

\section{CAPACIDADE DE INOVAÇÃO DA FIRMA}

A inovação do ponto de vista setorial pode ser entendida por diferentes abordagens, como no caso da conhecida taxonomia de Pavitt (1984) que descreve os padrões setoriais baseando-se nas fontes de tecnologia, nas fontes institucionais, na natureza da tecnologia produzida e nas características das firmas inovadoras. A sua taxonomia compreende firmas dominadas pelos fornecedores, firmas intensivas em produção, fornecedores de equipamentos especializados e aquelas baseadas na ciência.

Dosi (1988) e Malerba (2002) também abordam diferenças entre os setores em termos de conhecimento, das fontes de oportunidades tecnológicas, bem como do processo de aprendizagem que leva à inovação. Nesse sentido, observa-se que alguns setores são relacionados ao conhecimento científico, muitas vezes gerado nas universidades, enquanto que outros utilizam não os resultados da pesquisa básica, mas sim a aplicação gerada na indústria (DOSI, 1988; JENSEN et al., 2007; MALERBA \& ORSENIGO, 1997; ROBERTSON \& SMITH, 2008). Esses são comportamentos comumente vistos em setores tidos como de alta e de baixa tecnologia, respectivamente. Para Malerba (2002), as firmas são os agentes principais em um sistema setorial. Elas estão envolvidas na inovação, no processo produtivo, na venda dos produtos e na adoção e uso de determinadas tecnologias. Além disso, as firmas desenvolvem determinadas competências a partir de um acúmulo de conhecimento.

Assim, pode-se entender, que existe um ambiente que influencia a dinâmica setorial e, portanto, o comportamento e o desempenho das firmas. No entanto, apenas seguir o que é informado pelo ambiente pode não ser suficiente. A firma é um agente dinâmico, formado por um conjunto de recursos produtivos, com capacidade de 
adaptação ao ambiente, que aprende e evolui ao longo do tempo. $\mathrm{O}$ ato de inovar realizado pela firma é entendido como aquele capaz de diferenciá-la, proporcionando vantagens, mesmo que temporárias, manutenção, diversificação e, até mesmo, crescimento.

Por um tempo, esse crédito foi dado à capacidade tecnológica da empresa, principalmente a partir do trabalho seminal de Lall (1992). Para esse e outros autores que seguiram essa abordagem (BELL; PAVITT, 1995; KIM, 1999; PANDA; RAMANATHAN, 1996), a capacidade de inovação está diretamente ligada à capacidade tecnológica. A capacidade tecnológica é aquela encarregada de projetar e propor novas alternativas de valor em termos de novas tecnologias, novos processos ou novos produtos.

A partir de então, os estudos subsequentes começaram a discutir as teorias previamente levantadas pelos autores precursores no tema. Ocorreu, então, o desenvolvimento tanto de pesquisas empíricas como de pesquisas teóricas que visaram aprofundar o assunto, abordando a relação entre capacidade tecnológica e o sucesso da firma (HALL; BAGCHI-SEN, 2002; GARCIA-MUIÑA; NAVAS-LÓPEZ, 2007); realizando estudos setoriais (ARCHIBUGI; PIANTA, 1996; JIN; VON ZEDTWITZ, 2008); ou buscando identificar como as firmas apresentam desempenho distinto no mercado (FIGUEIREDO, 2009).

A capacidade tecnológica relacionada às atividades de P\&D ainda atualmente é considerada um fator-chave para a inovação das empresas. Diferentes autores relacionam a inovação à alocação de recursos às atividades de P\&D (ARCHIBUGl; PIANTA, 1996; TSAI, 2004; REICHERT et al., 2011; REICHERT; ZAWISLAK, 2014); à intensidade da atividade de P\&D (HALL; BAGCHI-SEN, 2002; MADANMOHAN et al., 2004; COOMBS; BIERLY, 2006); à cooperação, colaboração e parceria nas atividades de P\&D (LALL, 1992) e; à estruturação de um departamento de P\&D na empresa (ARCHIBUGI; PIANTA, 1996). Lourdes e Figueiredo (2009), nesta linha, apresentaram em 2009 um estudo a respeito dos méritos e limitações de abordagens a respeito da mensuração da capacidade tecnológica inovadora de firmas.

Porém, a capacidade tecnológica é necessária, mas não suficiente para se compreender a dinâmica inovativa da firma. Destaca-se que a percepção da inovação unicamente pela capacidade tecnológica "tem se demonstrado cada vez mais 
limitada, principalmente quando posta à prova de realidades econômicas menos privilegiadas nesse tipo de investimento ou atividade" (REICHERT et al., 2015, p.164). O que pode-se considerar a realizada brasileira.

Nesta linha, outras pesquisas passaram a abordar a capacidade de inovação incluindo outros elementos. O termo capacidades de inovação passa a se apresentar, portanto, como uma forma de ampliar os meios de perceber a inovação nas empresas. Para van Hemert, Nijkamp e Masurel (2013), as capacidades de inovação são um conjunto de características da firma que dão apoio e facilitam as suas estratégias de inovação e que, portanto, estimulam o desempenho inovativo. Para Peng et al. (2007), a capacidade de inovação está associada a melhorias, e trata, principalmente, da busca por novas tecnologias, desenvolvimento de equipamentos e processos, e desenvolvimento multidisciplinar de novos produtos.

Guan e Ma (2003) e Yam et al. (2004), com o intuito de mensurar a capacidade de inovação, consideraram sete dimensões da capacidade de inovação que poderiam determinar o desempenho da firma: capacidade de aprendizagem, de P\&D, de manufatura, de marketing, de organização, de alocação de recursos e de planejamento estratégico. Wang et al. (2008) como o intuito de avaliar a capacidade de inovação das firmas, os autores utilizaram cinco elementos: capacidades de P\&D, capacidades de decisão sobre inovação, capacidades de marketing, capacidades de produção e capacidades de capital.

Valladares et al. (2014), por sua vez, buscaram identificar os fatores determinantes e resultantes da capacidade de inovação. A partir de uma revisão sistemática de literatura, encontraram os seguintes fatores: liderança transformadora, intenção estratégica de inovar, gestão de pessoas para inovação, conhecimento do cliente e do mercado, gestão estratégica da tecnologia, organicidade da estrutura organizacional, gestão de projetos, e desempenho em inovação.

O que direcionou os estudos na tentativa de ampliar as explicações referentes à capacidade de inovar da firma foi a lógica de que diferentes empresas podem apresentar diferentes tipos de inovação em seu ciclo de vida e os diferentes tipos de inovação, bem como os seus graus de novidade, não são, necessariamente, explicados exclusivamente pela questão tecnológica. Nem todas as empresas podem 
(ou pretendem) atingir a fronteira tecnológica, no entanto, seu sucesso no mercado pode ser explicado por outros tipos de inovação, que exige outros tipos de capacidade.

Assim, de um lado, existem os estudos focados apenas na dimensão tecnológica da firma como meio de inovar e, de outro, autores que acabaram expandindo esse conceito. No último caso, começam a aparecer dificuldades de mensuração e de identificar a fronteira entre as diferentes dimensões. Utilizando os estudos de Guan e Ma (2003) e Yam et al. (2004) como exemplo, surgem dúvidas sobre qual a fronteira entre a dimensão de alocação de recursos e a de organização ou de alocação de recursos e manufatura, ou a fronteira entre planejamento estratégico e marketing ou planejamento estratégico e organização. Nesse sentido, para o estudo proposto foi necessário identificar um modelo de capacidades de inovação que não fosse restrito à capacidade tecnológica, nem tão abrangente que dificultasse a identificação dos limites das outras dimensões também consideradas. Assim, o modelo de quatro capacidades de inovação proposto por Zawislak et al. (2012; 2013a) mostrou-se relevante e, portanto, foi utilizado como instrumento para a presente pesquisa.

O modelo de capacidades de inovação de Zawislak et al. (2012; 2013a) pressupõe que a firma sempre realizará quatro funções básicas, divididas em duas dimensões. A dimensão tecnológica, que tem grande influência da literatura que discute capacidade tecnológica, considera as funções de desenvolvimento e de operação. A dimensão de negócios, que busca efetivamente ultrapassar a fronteira da capacidade tecnológica e abranger outros aspectos importantes para a inovação nas firmas, inclui as funções de gestão e de transação. Cada uma dessas funções corresponde a uma capacidade específica: de desenvolvimento, de operação, de gestão e de transação, conforme demonstrado na Figura 1. 
Figura 1 - Modelo das capacidades de inovação da firma

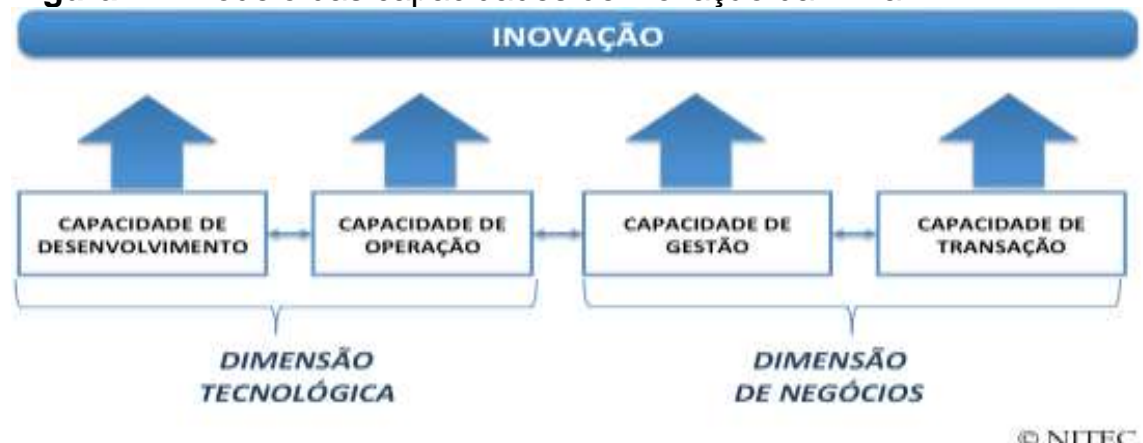

Fonte: Zawislak et al. (2012; 2013a)

A capacidade de desenvolvimento envolve atividades de aquisição de tecnologias, adaptação para às necessidades da firma e o desenvolvimento de novas tecnologias (LALL, 1992; BELL; PAVITT, 1995; IAMMARINO, PADILLA-PÉREZ, VON TUNZELMANN, 2008). A capacidade de operação inclui o controle de qualidade e a melhoria contínua, o sistema produtivo, bem como a sua flexibilidade (HAYES; PISANO, 1994; CHANDLER, 1990; SOLOW, 1957). A capacidade de gestão trata de itens como o monitoramento dos objetivos da firma, a tomada de decisão, a gestão dos recursos e a integração das áreas (PENROSE, 1959; BARNARD, 1966; MINTZBERG, 1973; CHANDLER, 1977). Por fim, a capacidade de transação inclui o relacionamento tanto com fornecedores como com clientes, além de aspectos mercadológicos e de logística e distribuição (COASE, 1937; WILLIAMSON, 1985; 1999; 2002; MADHOK, 1996; LANGLOIS; FOSS, 1999).

As capacidades se articulam segundo a própria lógica de existência e natureza da firma: da ideia (capacidade de desenvolvimento) à venda (capacidade de transação), passando pela produção física (capacidade de operação), seguindo uma coordenação eficiente das atividades (capacidade de gestão) que visa à remuneração dos fatores e dos ativos da firma (ZAWISLAK et al., 2012).

Estudos empíricos (Quadro 1) que aplicaram esse modelo das quatro capacidades de inovação da firma (ZAWISLAK et al., 2012; 2013a), mostram que em todas as quatro dimensões existem mudanças que podem afetar o desempenho inovativo das firmas. Conforme o modelo proposto, as firmas possuem as quatro capacidades, ou seja, nenhuma delas é nula, e ainda pode-se observar a predominância de uma delas. 
Quadro 1 - Resumo das características das capacidades identificadas em estudos empíricos baseados no Modelo das Capacidades de Inovação (continua)

\begin{tabular}{|c|c|c|c|c|c|}
\hline \multirow{2}{*}{$\begin{array}{l}\text { Estudos } \\
\text { Empíricos }\end{array}$} & \multirow[t]{2}{*}{ Setores analisados } & \multicolumn{4}{|c|}{ Principais características identificadas das capacidades } \\
\hline & & Desenvolvimento & Gestão & Operação & Transação \\
\hline $\begin{array}{l}\text { Estudo 1: } \\
\text { análise de } 19 \\
\text { empresas. } \\
\text { (Zawislak et al., } \\
\text { 2012) }\end{array}$ & $\begin{array}{l}\text { Empresas de setores } \\
\text { industriais diversos (ex.: } \\
\text { calçados, bebidas, } \\
\text { eletrônicos, plástico e } \\
\text { confecções); } \\
\text { Presença das quatro } \\
\text { capacidades nas } \\
\text { empresas (em } \\
\text { intensidades diferentes). }\end{array}$ & $\begin{array}{l}\text { A partir de mudanças nas } \\
\text { normas técnicas e novas } \\
\text { legislações ou } \\
\text { regulamentos; } \\
\text { Por requisito de clientes } \\
\text { ou fornecedores; } \\
\text { Inviabilidade de um } \\
\text { departamento de P\&D } \\
\text { permanente. }\end{array}$ & $\begin{array}{l}\text { Considerável grau } \\
\text { de informalidade nos } \\
\text { procedimentos. }\end{array}$ & $\begin{array}{l}\text { Operacionalização das } \\
\text { atividades de acordo } \\
\text { com as necessidades } \\
\text { dos clientes; } \\
\text { Capacidade de } \\
\text { produção limitada; } \\
\text { Ganho de agilidade } \\
\text { quando a demanda } \\
\text { atinge um pico } \\
\text { previsto. }\end{array}$ & $\begin{array}{l}\text { Parceria } \\
\text { comercial; } \\
\text { Vendas de forma } \\
\text { terceirizada. }\end{array}$ \\
\hline $\begin{array}{l}\text { Estudo 2: } \\
\text { análise de } 4 \\
\text { empresas } \\
\text { (Zawislak et al., } \\
\text { 2013a) }\end{array}$ & $\begin{array}{l}\text { Eletrônicos, Calçados, } \\
\text { Metais e Bebidas; } \\
\text { Destaque para as } \\
\text { diferentes capacidades } \\
\text { em cada empresa: } \\
\text { operacional } \\
\text { (Eletrônicos), gestão } \\
\text { (Calçados), tecnológica } \\
\text { (Metais) e operacional } \\
\text { (Bebidas). }\end{array}$ & $\begin{array}{l}\text { Existência de } \\
\text { departamento de P\&D. }\end{array}$ & $\begin{array}{l}\text { Tomada de decisão } \\
\text { de acordo com as } \\
\text { soluções destinadas } \\
\text { a produtos. }\end{array}$ & $\begin{array}{l}\text { Produção puxada a } \\
\text { partir dos pedidos de } \\
\text { clientes. }\end{array}$ & $\begin{array}{l}\text { Criação de } \\
\text { soluções a partir } \\
\text { da necessidade } \\
\text { de clientes; } \\
\text { Entregas rápidas; } \\
\text { Ações de } \\
\text { marketing; } \\
\text { Atendimento } \\
\text { especializado ao } \\
\text { cliente. }\end{array}$ \\
\hline $\begin{array}{l}\text { Estudo 3: } \\
\text { análise de } 14 \\
\text { empresas } \\
\text { (Zawislak et al., } \\
\text { 2013b) }\end{array}$ & $\begin{array}{l}\text { Empresas de setores de } \\
\text { baixa intensidade } \\
\text { tecnológica; } \\
\text { Presença das quatro } \\
\text { capacidades nas } \\
\text { empresas } \\
\text { (especialmente da } \\
\text { capacidade de } \\
\text { transação). }\end{array}$ & $\begin{array}{l}\text { Desenvolvimento e } \\
\text { lançamento de novos } \\
\text { produtos. }\end{array}$ & $\begin{array}{l}\text { Novas formas de } \\
\text { organização; } \\
\text { Implementação de } \\
\text { sistemas } \\
\text { operacionais; } \\
\text { Estabelecimento de } \\
\text { programas de } \\
\text { qualidade. }\end{array}$ & $\begin{array}{l}\text { Novos processos; } \\
\text { Automação de } \\
\text { processos; } \\
\text { Aquisição de máquinas } \\
\text { e equipamentos. }\end{array}$ & $\begin{array}{l}\text { Novas estratégias } \\
\text { comerciais; } \\
\text { Novos nichos de } \\
\text { mercado; } \\
\text { Novas marcas; } \\
\text { Verticalização } \\
\text { dos processos de } \\
\text { vendas. }\end{array}$ \\
\hline
\end{tabular}


Quadro 1 - Resumo das características das capacidades identificadas em estudos empíricos baseados no Modelo das Capacidades de Inovação (conclusão)

\begin{tabular}{|c|c|c|c|c|c|}
\hline \multirow{2}{*}{$\begin{array}{l}\text { Estudos } \\
\text { Empíricos }\end{array}$} & \multirow[t]{2}{*}{ Setores analisados } & \multicolumn{4}{|c|}{ Principais características identificadas das capacidades } \\
\hline & & Desenvolvimento & Gestão & Operação & Transação \\
\hline $\begin{array}{l}\text { Estudo 4: } \\
\text { análise de } 44 \\
\text { empresas } \\
\text { (Zawislak et al., } \\
\text { 2013) }\end{array}$ & $\begin{array}{l}\text { Empresas de setores } \\
\text { industriais diversos, } \\
\text { classificados por } \\
\text { intensidade tecnológica; } \\
\text { Empresas classificadas } \\
\text { conforme o tipo de } \\
\text { inovação: empresa } \\
\text { tecnológica, operacional, } \\
\text { gerencial e transacional. }\end{array}$ & $\begin{array}{l}\text { Existência de estrutura } \\
\text { formal de P\&D; } \\
\text { Interação com instituições } \\
\text { de pesquisa; } \\
\text { Desenvolvimento de } \\
\text { novos produtos; } \\
\text { Aplicação de novos } \\
\text { materiais. }\end{array}$ & $\begin{array}{l}\text { Gestão profissional; } \\
\text { Estrutura de } \\
\text { governança; } \\
\text { Estrutura complexa; } \\
\text { Decisões } \\
\text { descentralizadas; } \\
\text { Planejamento } \\
\text { estratégico formal. }\end{array}$ & $\begin{array}{l}\text { Produção de produtos } \\
\text { customizados; } \\
\text { Uso de sistemas just in } \\
\text { time e kanban; } \\
\text { Produção flexível. }\end{array}$ & $\begin{array}{l}\text { Ações de } \\
\text { marketing; } \\
\text { Habilidades de } \\
\text { negociação; } \\
\text { Foco na cadeia } \\
\text { de suprimentos; } \\
\text { Relações de } \\
\text { longo prazo; } \\
\text { Marca. }\end{array}$ \\
\hline $\begin{array}{l}\text { Estudo 5: } \\
\text { análise de } 4 \\
\text { empresas } \\
\text { (Ruffoni et al., } \\
\text { 2015) }\end{array}$ & $\begin{array}{l}\text { Calçados; } \\
\text { Destaque para as } \\
\text { diferentes capacidades } \\
\text { em cada empresa } \\
\text { (apesar de serem do } \\
\text { mesmo setor produtivo). }\end{array}$ & $\begin{array}{l}\text { Inovação de produto } \\
\text { incremental; } \\
\text { Investimento em P\&D; } \\
\text { Concepção e modelagem } \\
\text { dos produtos. }\end{array}$ & $\begin{array}{l}\text { Contratação ou } \\
\text { treinamento de mão } \\
\text { de obra qualificada. }\end{array}$ & $\begin{array}{l}\text { Preocupação com a } \\
\text { qualidade dos produtos } \\
\text { e processos. }\end{array}$ & $\begin{array}{l}\text { Investimento feito } \\
\text { no } \\
\text { desenvolvimento } \\
\text { de produtos com } \\
\text { base na } \\
\text { exploração das } \\
\text { tendências de } \\
\text { mercado. }\end{array}$ \\
\hline $\begin{array}{l}\text { Estudo 6: } \\
\text { análise de } 1331 \\
\text { empresas } \\
\text { (Reichert et al., } \\
2015 \text { ) }\end{array}$ & $\begin{array}{l}\text { Empresas de todos os } \\
\text { setores industriais }\end{array}$ & $\begin{array}{l}\text { Desenvolvimento de } \\
\text { produto a partir da } \\
\text { solicitação de clientes ou } \\
\text { melhorias em produtos } \\
\text { existentes; } \\
\text { desenvolvimento } \\
\text { constante por pessoal } \\
\text { especializado; falta de } \\
\text { organização das } \\
\text { atividades de } \\
\text { desenvolvimento. }\end{array}$ & $\begin{array}{l}\text { Programação da } \\
\text { produção a partir da } \\
\text { capacidade } \\
\text { instalada; inovação } \\
\text { por melhoria de } \\
\text { processos e } \\
\text { aquisição de } \\
\text { máquinas e } \\
\text { equipamentos. }\end{array}$ & $\begin{array}{l}\text { Decisões } \\
\text { condicionadas ao } \\
\text { passado; empresas } \\
\text { com modelo de gestão } \\
\text { familiar. }\end{array}$ & $\begin{array}{l}\text { Empresas em } \\
\text { meio de cadeia; o } \\
\text { preço de venda } \\
\text { do produto é } \\
\text { definido pelo } \\
\text { custo; mudanças } \\
\text { nos processos de } \\
\text { negociação. }\end{array}$ \\
\hline
\end{tabular}


Verifica-se no Quadro 1 que a aplicação do modelo das capacidades de inovação até os últimos estudos descritos acima (de 2015) deu-se em setores de atividades manufatureiras industriais. Além disso, em torno de $75 \%$ das empresas industriais do Rio Grande do Sul (RS) - estado onde localizam-se as firmas nas quais foram feitos os testes empíricos deste modelo -, são de baixa ou média-baixa intensidade tecnológica (REICHERT et al., 2015), reforçando, portanto, a relevância de se estudar firmas do RS deste grupo de intensidade tecnológica. Para ampliar a discussão, objetiva-se, neste trabalho, examinar como as capacidades de inovação da firma se comportam em firmas do setor agroindustrial.

Assim, apresenta-se novamente a pergunta: empresas agroindustriais, que pertencem a setores de baixa intensidade tecnológica, possuem capacidade de inovação? Quais são suas características?

\section{PROCEDIMENTOS METODOLÓGICOS}

Utilizou-se o método descritivo de estudo de casos. Foram estudadas duas empresas do setor do agronegócio da região dos Campos de Cima da Serra do Rio Grande do Sul que realizaram um processo de mudança tecnológica e agregaram mais valor aos seus produtos e processos produtivos, sendo possível analisar a capacidade de inovação destas empresas que se caracterizam por serem de baixa intensidade tecnológica. Releva destacar que a região escolhida se justifica pela existência nela de um importante setor econômico de baixa tecnologia (low-tech) e que em tal região poucas empresas se dispuseram a realizar as entrevistas da pesquisa aqui relatada. Por conta disso, optou-se pela realização de dois casos estruturados e aprofundados.

Para manter o nome das empresas em sigilo, elas foram apresentadas pelos nomes fictícios, SOL e RENOVA. Os dados para a pesquisa foram coletados em duas etapas ao longo do ano de 2013. Na primeira etapa foram coletadas informações de fontes secundárias (sites das empresas, artigos e jornais) e na segunda foram realizadas entrevistas em profundidade (presenciais e individuais) com os proprietários e profissionais conhecedores das rotinas relativas à geração da inovação nas quatro áreas investigadas: produção, desenvolvimento, gestão e comercialização. 
A pesquisa foi realizada a partir da utilização de um roteiro ${ }^{3}$ de entrevista semiestruturado.

Juntamente com as entrevistas, que foram duas por empresa, foram realizadas visitas técnicas às instalações das empresas, buscando-se complementar e confirmar algumas das informações comunicadas pelos entrevistados. Ao final das entrevistas e visitas, as informações foram transcritas, confirmadas com os entrevistados, classificadas e analisadas.

\footnotetext{
${ }^{3} \mathrm{O}$ roteiro de perguntas utilizado foi extraído do instrumento de pesquisa elaborado no âmbito do projeto de pesquisa "Caminhos da Inovação da Indústria Gaúcha". Esta pesquisa foi realizada por um consórcio formado por universidades gaúchas, financiado pela FAPERGS e CNPq, e coordenado pelo Núcleo de Estudos em Inovação (NITEC) da Escola de Administração (EA) da UFRGS. As questões são divididas em quatro blocos, cada um cobrindo uma das quatro capacidades. As questões eram abrangentes sobre cada função da empresa, permitindo que o entrevistado descrevesse todos os processos relativos a cada uma dessas áreas.
} 
Quadro 2 - Resumo das informações obtidas em fontes secundárias e entrevistas presenciais

\begin{tabular}{|c|c|c|c|c|}
\hline \multirow{2}{*}{$\begin{array}{l}\text { Agroindústria } \\
\text { pesquisada }\end{array}$} & \multicolumn{4}{|c|}{ Fontes de informações secundárias e entrevistas } \\
\hline & Revistas & Jornais & Site & $\begin{array}{l}\text { Entrevistas presenciais realizadas por } \\
\text { pesquisadora }\end{array}$ \\
\hline $\mathbf{S}$ & $\begin{array}{lr}\text { Informações } & \text { a } \\
\text { respeito da empresa } \\
\text { na revista } & \text { Rural } \\
\text { Centro, } & \text { essas } \\
\text { informações foram } \\
\text { sobre a consolidação } \\
\text { e crescimento de } \\
\text { agroindústrias no Rio } \\
\text { Grande do Sul. }\end{array}$ & $\begin{array}{l}\text { Foram } \\
\text { encontradas } \\
\text { informações no } \\
\text { jornal Correio } \\
\text { Vacariense } \\
\text { sobre produtos } \\
\text { orgânicos. }\end{array}$ & $\begin{array}{l}\text { A empresa } \\
\text { possui site com } \\
\text { toda a linha de } \\
\text { produtos. } \\
\text { Informações } \\
\text { referentes a isso } \\
\text { foram coletadas } \\
\text { em agosto de } \\
2012 \text { e depois } \\
\text { confirmadas em } \\
\text { outubro de } \\
2013 \text {. }\end{array}$ & $\begin{array}{l}\text { A primeira entrevista realizada foi em } 12 \text { de } \\
\text { setembro de 2013, no galpão de depósito da } \\
\text { empresa localizado em Vacaria. A entrevista foi } \\
\text { entrevistada com um dos sócios e responsável pela } \\
\text { administração } \\
\text { A segunda entrevista ocorreu em } 19 \text { de setembro de } \\
2013 \text { com o outro sócio da empresa e também } \\
\text { responsável pela administração e pela produção, na } \\
\text { sede administrativa da empresa. Todas as } \\
\text { informações foram transcritas e validadas pelos } \\
\text { entrevistados e em } 28 \text { de setembro de } 2013 \text {, foi feita } \\
\text { nova entrevista presencial com o primeiro } \\
\text { entrevistado listado para confirmar algumas } \\
\text { informações coletadas anteriormente. }\end{array}$ \\
\hline RENOVA & $\begin{array}{l}\text { Foram encontradas } \\
\text { reportagem sobre } \\
\text { essa agroindústria na } \\
\text { Revistar Granja, } \\
\text { trazendo informações } \\
\text { a respeito de novas } \\
\text { culturas agrícolas } \\
\text { alternativas. }\end{array}$ & $\begin{array}{l}\text { Foram coletadas } \\
\text { informações no } \\
\text { Jornal } \\
\text { Florense } \\
\text { durante o ano de } \\
2012 \text {. }\end{array}$ & $\begin{array}{l}\text { Informações } \\
\text { sobre linha de } \\
\text { produtos } \\
\text { história } \\
\text { empresa } \\
\text { coletadas em } \\
\text { agosto de } 2013 \text {. }\end{array}$ & $\begin{array}{l}\text { A primeira entrevista foi realizada com o } \\
\text { responsável pelos setores comercial e de produção } \\
\text { da empresa, feita no dia } 06 \text { de outubro de } 2013 \text {. A } \\
\text { segunda entrevista foi feita com o proprietário da } \\
\text { empresa no dia } 11 \text { de outubro de } 2013 \text {, na sede } \\
\text { campestre da empresa. Todas as informações } \\
\text { foram transcritas e validadas pelos entrevistados. }\end{array}$ \\
\hline
\end{tabular}




\section{CARACTERÍSTICAS DAS CAPACIDADES DE INOVAÇÃO}

O setor agroindustrial é considerado um setor de baixo nível de investimento em P\&D, mas com crescente fluxo de lançamento de novos produtos, e com a absorção crescente de tecnologias provenientes de outros setores (RÉVILLION et al., 2004).

As duas firmas pesquisadas neste estudo utilizam pequenos frutos como matéria-prima para os seus produtos. Segundo Pagot (2010), a produção de pequenas frutas na região dos Campos de Cima da Serra está em desenvolvimento e vislumbram-se muitos desafios para o aperfeiçoamento desta cadeia de produção.

De acordo com a Empresa de Assistência Técnica e Extensão Rural EMATER/RS (2010), as agroindústrias da região dispõem de maçã, amora, morango, marmelo, physalis, framboesa, pêssego e uva bordô como matérias-primas. Nos últimos anos, as pequenas frutas têm chamado a atenção dos consumidores em função da sua qualidade sensorial e nutricional (alimentos funcionais).

A colheita de pequenas frutas é realizada manualmente por agricultores familiares ou trabalhadores contratados por períodos não contínuos. As frutas podem ser selecionadas no momento da colheita, diretamente nas embalagens em que serão comercializadas, ou em packinghouses de empresas especializadas (PAGOT, 2010).

A transformação das frutas em polpas é um processo utilizado por agroindústrias como forma de agregar valor ao produto final (fruta in natura). As polpas podem ser comercializadas como 'polpa natural congelada' em embalagens pequenas para preparação de sucos ou ainda em embalagens maiores para o uso em maior escala pela indústria de alimentos (FELLOWS, 2006).

A seguir discorre-se a respeito das características das empresas analisadas no que tange ao comportamento inovativo, buscando caracterizar e identificar as capacidades de inovação de cada empresa.

\subsection{Firmas Investigadas}

As informações das empresas estão organizadas da seguinte forma: formação 
histórica e características das capacidades de inovação. Primeiro é analisada a empresa SOL e, na sequencia, a empresa RENOVA.

\subsubsection{SOL}

A empresa SOL iniciou suas atividades na década de 1950 com o cultivo de grãos. Na década de 1970 a família já produzia geleias de frutas de vários sabores tanto para o consumo próprio como para venda. Em 1993 iniciou a produção de hortifrutigranjeiros agroecológicos que eram comercializados em feiras e mercados locais. A ideia de inserir produtos agroecológicos no negócio veio de um dos descendentes da família, pelo fato de dominar o conhecimento tecnológico necessário para isso, pelo fato de ter se formado técnico agrícola com experiência em um centro ecológico.

Em 1994, além de aumentar o volume produzido, os empresários voltaram-se a desenvolver esforços para agregar valor ao produto final. No ano 2000, juntamente com outras famílias, fundaram a 'Associação de Agricultores Ecologistas', cujo objetivo era de promover a sustentabilidade econômica das famílias de produtores associados, por meio de uma produção agroecológica e comércio mais honesto.

Na mesma época, a empresa iniciou a produção artesanal de geleias e doces. Em 2001, encaminhou projeto para financiamento junto ao 'Programa Rio Grande Ecologizar', da Secretaria da Agricultura Familiar, com o objetivo de ser um programa de produção, agroindustrialização e comercialização de produtos ecológicos, buscando promover a transição do modelo convencional para uma agricultura de base ecológica, através de ações de suporte e financiamento do Estado.

A produção industrial e a comercialização de doces em calda, conservas, geleias e extrato de tomate iniciaram em 2003. Posteriormente, houve ampliação da produção de frutas e formação de parcerias com produtores de diferentes regiões do Estado. Devido à crescente demanda e à ideia de prospectar novos mercados, outros produtos foram implementados à produção, tais como doces de corte, geleias sem adição de açúcar e, entre 2005 e 2006, sucos integrais, destacando-se a produção de suco de uva bordô integral. O crescimento da produção gerou a necessidade da 
ampliação das instalações físicas. Atualmente, a SOL comercializa seus produtos nos mercados regional e nacional.

A empresa conta com cinco funcionários na entressafra e de dez a doze funcionários no período de safra, além dos quatro membros da família. De 35 a 40\% da produção anual é produzida na própria propriedade. O produto que predomina é o suco de uva bordô, que representa $55 \%$ das vendas. Os produtos novos são geleia de frutas vermelhas, mirtilo, kiwi, laranja, e as geleias sem açúcar de maçã, mirtilo e néctar de uva.

Em relação a capacidade de inovação da firma, destaca-se inicialmente uma dimensão desta capacidade, que é a capacidade de desenvolvimento. Nesta, destaca-se o processo de desenvolvimento de novos produtos que ocorre em resposta a necessidades do mercado. Os produtos orgânicos são feitos para clientes que pedem um novo sabor ou produto e estão dispostos a pagar por um valor agregado maior. A partir disso, a empresa analisa sua capacidade para produzir o produto desejado e toma uma decisão. Já os produtos que não são orgânicos, são produzidos com matéria-prima que vem de produtores ainda não certificados e, portanto, de menor preço. O desenvolvimento desses produtos é geralmente feito para clientes que visam preços mais baixos.

A empresa participa de feiras, eventos e cursos para adquirir novos conhecimentos. Para a decisão de produzir um novo produto, são analisados a disponibilidade de matéria prima, a capacidade e o custo de produção. Por fim, verifica-se a viabilidade operacional e mercadológica do produto. Por motivos de certificação, os produtos passam por etapas de testes antes de serem produzidos para venda. Atualmente, estão em teste produtos que utilizam frutas nativas, como uvaia, butiá e guamirim.

A empresa compreende que suas atividades de desenvolvimento estão de acordo com seus concorrentes nacionais de mesmo porte. Trata-se de um setor de baixa intensidade tecnológica que trabalha com produtos tradicionais e tecnologia madura. Em nível internacional a empresa informa trabalhar com tecnologia inferior à dos concorrentes.

Para a SOL, inovação significa fazer diferente no processo de produção e oferecer novos produtos aos clientes. Desenvolver produtos com uso de frutas nativas 
e projetos que assumam maior proporção nas vendas são as metas da empresa. Objetiva lançar três novos produtos que sejam inovações para o mercado regional ou nacional. Umas das principais mudanças ocorridas foi a melhoria do processo produtivo pela compra de um bem de capital, uma caldeira. A SOL se preocupa em realizar de forma adequada o cálculo do custo dos produtos e a quantidade de entregas terceirizadas. Objetiva aumentar o número de clientes e atingir mercados em cidades distintas. Em termos de relacionamento com os fornecedores, está sempre em busca de novas parcerias.

A segunda dimensão analisada da capacidade de inovação, é a capacidade de operação. Cada produto segue uma série de etapas para cumprir o seu processo produtivo, o qual pode incluir a seleção das frutas, lavagem, despolpa, extração do suco, cozimento, resfriamento, envaze, estocagem e rotulagem. O processo utilizado não é considerado moderno, pois há empresas de maior porte que trabalham com esteira para o transporte dos produtos e processo de lacre automatizado. Para melhorar alguns processos produtivos, a SOL adquiriu uma nova caldeira, já mencionado, que contribuiu na redução de $30 \%$ do tempo de preparo dos produtos, pois automatizou parte do processo e, assim, reduziu o desgaste do operador que antes realizava o processo manualmente. No que tange à eficiência produtiva da empresa, sua compreensão é de estar em situação igual aos demais concorrentes, e ainda busca dominar o que eles ainda não trabalham. Quanto aos concorrentes internacionais, compete por preço de produtos da mesma linha.

A rotina operacional da empresa segue um cronograma, o qual nem sempre é rigidamente cumprido. Para todos os processos, existe controle de qualidade e, devido às certificações, o controle de qualidade ocorre desde a produção das frutas. Para a operacionalização dos novos processos da empresa, os gestores fazem cursos, como de boas práticas, e vão a feiras específicas. A empresa também conta com a assistência técnica de um enólogo para auxiliar na produção dos sucos. O maior problema que ocorre na produção refere-se à sazonalidade e grande demanda para processamento da matéria-prima, pois o período de colheita das frutas é na mesma época.

Em termos de capacidade de gestão, os processos administrativos da empresa estão centrados nos sócios que, juntamente com outros membros da família, 
tomam as decisões na empresa. A integração das diversas áreas da empresa acontece por reuniões com os líderes e demais funcionários. Também são realizados trabalhos motivacionais que contribuem com o planejamento e cronograma das atividades. A empresa não tem problema com a rotatividade da mão de obra, mas sim, em conseguir novos funcionários qualificados, pois a localização rural da empresa dificulta a contratação.

A capacidade de transação é caracterizada por questões como o fato da empresa fazer esforços e ter uma rotina destinada a manter contato com clientes, captar novos clientes e apresentar seus produtos em feiras - por meio do envio de amostras da produção. Os principais clientes têm lojas de produtos orgânicos ou ecológicos. Vende-se também para mercados institucionais (ex.: escolas e hospitais). A SOL também se relaciona com cooperativas parceiras para oferecer seus produtos. A empresa participa do circuito de comercialização da Rede Eco-vida, uma forma de certificação que garante a qualidade do produto ecológico, permite o respeito e a valorização da cultura local através da aproximação de agricultores e consumidores. O circuito funciona com base em estações regionais onde é feita a distribuição dos produtos da agricultura familiar para a comercialização.

A maioria das matérias primas são adquiridas em cooperativa de produtores orgânicos localizada no município da empresa. A empresa realiza de dois a três planejamentos de compras antes da safra, organiza meta de produção e realiza reunião com os produtores. As compras de outros insumos são feitas no início da safra para garantir preço.

$\mathrm{Na}$ percepção dos entrevistados, os clientes compram o produto pela qualidade, pois muitas vezes ele não é o mais competitivo em preço. A empresa define o preço do produto através de cálculo de custo e não tem margem uniforme. No caso dos sucos, seus custos são superiores aos dos concorrentes devido à melhor tecnologia que esses possuem, nos demais produtos o custo é semelhante. Conforme os entrevistados, a marca da empresa é valorizada e reconhecida no mercado. Em 2013 a empresa foi premiada pela qualidade dos produtos. Alguns produtos estão no mercado com o objetivo principal de divulgar a marca, pois não apresentam retorno financeiro. Os representantes também desempenham papel importante, pois 
informam à empresa as tendências de mercado após realizarem o processo de pósvenda e visita aos clientes.

Conforme a empresa, a ordem de importância das dimensões que formam a capacidade inovação é: 1) Transação; 2) Gestão; 3) Operação e 4) Desenvolvimento. Para a empresa, as capacidades de transação e gestão se complementam porque a firma precisa ter uma boa gestão e foco no mercado para obter respostas adequadas no processo de comercialização. Atentam, porém, para o fato de que nem sempre foi assim na SOL, pois no início das atividades o foco estava na produção e, somente depois, conseguiam dar atenção para a comercialização, gestão e tecnologia.

Entende-se, assim, que o modelo das quatro capacidades utilizado auxilia a compreender a capacidade inovativa da SOL por permitir visualizar que o seu desenvolvimento na capacidade de transação contribui efetivamente para seu aprendizado nas dimensões de gestão, operação e desenvolvimento. O raciocínio deve seguir de forma dinâmica e, portanto, entende-se que as habilidades da firma nas outras dimensões reforçam o diferencial nas transações e assim sucessivamente. Portanto, no modelo utilizado consegue-se visualizar que a SOL é uma empresa inovadora, não com foco em tecnologia e inovações tecnológicas de impacto, mas sim inovadora essencialmente na forma de transacionar seu produto no mercado. Tal capacidade deve ser considerada também como uma capacidade de inovação.

\subsubsection{RENOVA}

A história desta firma inicia com a atividade de um produtor rural que começou a trabalhar no campo ainda na infância, junto com seus familiares. A principal cultura praticada pela família era a produção de uvas. Em busca de diversificação, a família começou a cultivar hortifrutigranjeiros (beterraba, cenoura e alho). Não sendo possível ampliar a atividade, em função das características da terra destinada a isso, o produtor decidiu, em parceria com um colega, arrendar áreas para a ampliação da produção de suas culturas.

O colega possuía experiência na cultura do morango e, portanto, em 2004, passaram a plantar a fruta, cultura que se adaptou muito bem ao clima e deu uma boa rentabilidade aos produtores. Nos anos seguintes, a cultura de morango foi ampliada 
e uma estrutura de logística foi criada e acompanhou a ampliação do cultivo. As mudas eram importadas por dois fornecedores. Em 2007, além de continuar ampliando a cultura de morango, o produtor arrendou mais terras, dessa vez cultivando pomares de maçã.

Com o crescimento rápido do negócio, investiu em controles administrativos. Em 2010, com o incentivo da Secretaria da Agricultura do município, o produtor passou a motivar pequenas famílias do município a produzir a fruta. Dá-se então início ao sistema de parceria em que outros produtores produzem e vendem para o produtor fundador da empresa revender. A iniciativa se expandiu por mais municípios. A logística, em função disso, passou a contar com nove veículos com câmaras de resfriamento para o transporte adequado da fruta e o número de empregados atingiu o total de 160 e mais aproximadamente 30 safristas.

Como o objetivo era aproveitar o excedente de produção do morango, 0 produtor, em sociedade com outra pessoa com experiência de 26 anos em outra empresa do mesmo ramo, criou, em 2012, uma agroindústria para vender congelados de frutas. Para tornar a atividade da empresa viável, foram buscados novos municípios da região para explorar culturas distintas, como amora, mirtilo, framboesa e physalis. O produto que predomina atualmente é a amora congelada. Os clientes estão solicitando novas frutas congeladas como guabiju, pitanga e butiá (plantas nativas). Atualmente, a empresa atende, aproximadamente, um terço do mercado de congelados, e pretende aumentar o volume de produção para poder atender a novos mercados.

Para começar a atingir os objetivos almejados, a RENOVA buscou financiamento para a aquisição de máquinas e equipamentos necessários para a atividade. A empresa possui 15 funcionários, produz 1,5 toneladas de frutas congeladas e a pessoa física do produtor rural continua suas atividades paralelamente, produzindo e vendendo diretamente ao consumidor 8,5 toneladas de fruta in natura.

Em relação às dimensões da capacidade inovativa, inicia-se com a capacidade de desenvolvimento. Destaca-se que o processo de desenvolvimento de produtos é mínimo na empresa, pois as atividades são padronizadas. O que sofre alteração são as embalagens (rótulo e tamanho), dependendo das exigências do consumidor final 
(pessoa física ou outras empresas que produzem iogurte, geleias, sucos ou doces). No entanto, quando são inseridos novos produtos, eles são bem aceitos pelos funcionários. Segundo o proprietário, um dos respondentes da pesquisa, a capacidade de assimilação do conhecimento por parte dos funcionários é excelente, pois muitos já têm experiência em outras empresas com processo similar.

O nível de conhecimento, em comparação tanto com os concorrentes nacionais como os internacionais, é muito bom, segundo os proprietários. Após perceber que são necessárias mudanças e melhorias nos processos, aplica-se o conhecimento e tecnologia necessária para isso, adquirindo maquinário e qualificando os funcionários para trabalharem com o novo processo.

No que diz respeito à capacidade de operação, foram verificadas questões interessantes. As frutas chegam na empresa oriundas da produção própria ou de parcerias com produtores. Cada produto segue uma série de etapas para cumprir o seu processo produtivo, que pode incluir a classificação, lavagem, despolpa, corte, passagem pelo túnel de congelamento, embalagem e armazenamento em câmara fria.

Existe um cronograma diário para a as atividades produtivas, que varia bastante. A produção é controlada e disparada de acordo com a entrada da matériaprima e a solicitação dos pedidos de venda. O controle de qualidade existe, mas não é eficiente, é feito por pessoa pouco apta, que observa os processos, mas não tem registro sobre eles. Um dos principais problemas encontra-se no fato da não contratação de mão-de-obra especializada em tal atividade, visando não ampliar os custos. A empresa tenta aperfeiçoar as técnicas de trabalho dos funcionários, mas só internamente e informalmente. A RENOVA reconhece a necessidade dos funcionários fazerem cursos de controle de qualidade e boas práticas, mas ainda não pôs em prática tal forma de qualificação formal.

$\mathrm{Na}$ capacidade de gestão verificou-se que as decisões administrativas estão centradas em duas pessoas que são os sócios da empresa. A empresa não dispõe de estratégia específica. Os sócios indicam que a integração entre as diferentes áreas da empresa é boa, mas não possuem a rotina de reuniões para estipular metas ou objetivos. Tanto o planejamento como o controle é feito pelos sócios. A solução de 
problemas se dá na hora em que ocorre o evento, e não há acompanhamento ou posterior avaliação sobre eles.

Os esforços da RENOVA são voltados para o setor produtivo e comercial. A gestão da empresa, segundo os entrevistados, deveria melhorar, pois não há controles específicos, há organograma, mas ele não é seguido. Muitas coisas são decididas na hora, sem planejamento.

Por fim, a capacidade de transação caracteriza-se pela existência de uma estratégia comercial de fazer visitas aos clientes pessoalmente, para conversar com o responsável pelas compras e com os proprietários. Não existe atividade de marketing formal e o que ocorre é que os clientes novos são indicados pelos atuais. Também é feita pesquisa pela internet para identificar novos clientes. A RENOVA tenta acumular vários pedidos, para viabilizar a produção, fazendo a entrega (terceirizada) em roteiro preestabelecido.

O morango vem da produção rural da empresa, as demais frutas são adquiridas através de parceria com outros produtores na safra de cada fruta. As embalagens são compradas de acordo com as compras do ano anterior, e depois se necessário são feitas compras menores.

É feito cálculo de custo, mas também se analisa o mercado para alterar a margem de lucro. Imagina-se que a compra da fruta direto do produtor (parceiro) tem menor custo, mas essa informação não é formalizada. Há venda em atacado (em maior quantidade), e também em varejo (pequenos distribuidores), sendo que a decisão pela distribuição entre esses canais de venda depende da relação entre oferta e procura.

O pós-venda é realizado tanto por telefone como em visitas aos clientes. Os respondentes destacaram que a marca dos produtos da empresa é valorizada, bem aceita e elogiada. Segundo os entrevistados, os clientes compram os produtos pela qualidade, regularidade nas entregas e bom relacionamento entre empresa e clientes.

Por fim, destaca-se que a eficiência produtiva da RENOVA é muito boa se comparada com os concorrentes nacionais e internacionais. A empresa ainda não consegue exportar somente por uma questão de volume de produção insuficiente, e não por falta de qualidade ou padronização dos seus produtos, conforme os entrevistados. 
Os entrevistados, quando questionados a respeito da ordem de importância das quatro dimensões que constituem a capacidade inovativa, informaram o seguinte: 1) Operação 2) Transação 3) Gestão e 4) Desenvolvimento. Para a empresa, a ordem de prioridade é ter um produto de qualidade, ter um bom relacionamento com o cliente, gerir bem o negócio e, com isso, conseguir desenvolver novas soluções tecnológicas. A capacidade que se destaca é a de operação.

Novamente observa-se que a capacidade inovativa da firma não se centra na tecnologia (capacidade de desenvolvimento), como era de se esperar para empresas de baixa intensidade tecnológica. O que se destaca é a capacidade de operação. Isso é possível pelo uso de uma lente mais ampla, ou seja, de um modelo com conceito mais aberto de capacidade de inovação da firma, para observar a sua atividade inovativa.

\subsection{Síntese das características das capacidades de inovação das firmas SOL e RENOVA}

A capacidade de desenvolvimento da empresa SOL está presente de forma singela, os processos são os mesmos utilizados em outras empresas do mesmo segmento. Os produtos orgânicos produzidos pela empresa são para clientes que estão dispostos a pagar mais por este tipo de produto. A administração da empresa é centrada nos membros da família. A produção é programada conforme os pedidos colocados e a safra.

Já a capacidade de transação, que aparece de forma mais intensa, está relacionada à capacidade de adaptação que define a firma, demonstrada pela redução de custos e terceirização de logística e distribuição, participação em feiras nacionais, busca de novos clientes, promoção dos produtos pelo website, busca de novos mercados, como os institucionais e o circuito de comercialização.

A capacidade tecnológica da RENOVA aparece mais evoluída, comparada à empresa SOL. O responsável pelos produtos faz visitas a concorrentes nacionais e internacionais e os funcionários assimilam novos conhecimentos com facilidade. No entanto, a tecnologia utilizada nada se diferencia de processos já existentes no mercado e não há criação/ desenvolvimento de novos produtos. A gestão também é 
centrada, basicamente, nos membros da família, e a empresa não tem estratégia definida. A integração entre as diferentes áreas da empresa é adequada, mas não há rotinas (por exemplos, reuniões) que visem a definição conjunta de metas ou objetivos da firma. Observa-se uma busca pela redução de custos de transação em função da produção da própria fruta e do estabelecimento de parcerias com produtores locais. No entanto, o preço dos produtos acompanha o preço de mercado, não ocorrendo a obtenção pela firma de um preço premium.

A capacidade de operação mostrou-se, portanto, a mais desenvolvida, uma vez que as rotinas operacionais são padronizadas, o volume de produção é controlado, e há uma organização no sentido de definir a quantidade de produção a partir da solicitação dos pedidos de venda.

O QUADRO 3 sintetiza as características das capacidades de inovação das empresas analisadas, com base no modelo adotado. 


\begin{tabular}{|c|c|c|c|c|}
\hline \multirow[t]{2}{*}{ Firmas } & \multicolumn{4}{|c|}{ Principais Resultados } \\
\hline & Desenvolvimento & Gestão & Operação & Transação \\
\hline SOL & $\begin{array}{l}\text { Base tecnológica } \\
\text { pequena, processos já } \\
\text { existentes, e pouco } \\
\text { modernos, copiados de } \\
\text { outras agroindústrias. } \\
\text { Produtos orgânicos são } \\
\text { feitos para clientes que } \\
\text { querem pagar mais por } \\
\text { este produto. } \\
\text { Esses clientes podem } \\
\text { solicitar novos sabores ou } \\
\text { produtos e a empresa } \\
\text { analisa sua capacidade } \\
\text { produtiva. }\end{array}$ & $\begin{array}{l}\text { Administração familiar, as } \\
\text { decisões estão centradas } \\
\text { em duas pessoas que } \\
\text { fazem os processos } \\
\text { administrativos, além da } \\
\text { análise de mercado, } \\
\text { participam de feiras e } \\
\text { eventos e realizarem } \\
\text { reuniões com os líderes e } \\
\text { outros funcionários. }\end{array}$ & $\begin{array}{l}\text { Produção baseada nas } \\
\text { frutas da época e nos } \\
\text { pedidos dos clientes. } \\
\text { Para a operacionalização } \\
\text { dos novos processos, os } \\
\text { gestores fazem cursos e } \\
\text { vão a feiras específicas. }\end{array}$ & $\begin{array}{l}\text { Estratégia comercial inclui } \\
\text { participação em feiras } \\
\text { para captar novos } \\
\text { clientes. Possui website, } \\
\text { que divulga toda a linha } \\
\text { de produtos, e faz } \\
\text { consulta sobre possíveis } \\
\text { clientes. } \\
\text { Entregas terceirizadas. } \\
\text { Mercados institucionais. } \\
\text { Circuito de } \\
\text { comercialização, de } \\
\text { entrega, pós-venda, visita } \\
\text { aos clientes, e } \\
\text { representantes informam } \\
\text { sobre tendências de } \\
\text { mercado. }\end{array}$ \\
\hline RENOVA & $\begin{array}{l}\text { Conhecimento tecnológico } \\
\text { da empresa é equivalente } \\
\text { ou avançado em relação } \\
\text { aos concorrentes. O } \\
\text { responsável pela } \\
\text { produção já fez visita a } \\
\text { concorrentes nacionais, e } \\
\text { da Europa, Chile, México. } \\
\text { Funcionários assimilam } \\
\text { bem os novos } \\
\text { conhecimentos. }\end{array}$ & $\begin{array}{l}\text { As decisões gerenciais da } \\
\text { empresa são } \\
\text { centralizadas na família. } \\
\text { Não dispõe de estratégia } \\
\text { específica. } \\
\text { A integração entre as } \\
\text { diferentes áreas da } \\
\text { empresa é boa, mas não } \\
\text { há mecanismos que } \\
\text { estimulem a definição de } \\
\text { metas ou objetivos } \\
\text { corporativos. }\end{array}$ & $\begin{array}{l}\text { As rotinas operacionais } \\
\text { são padrão para esse tipo } \\
\text { de atividade. } \\
\text { A produção é disparada } \\
\text { de acordo com a entrada } \\
\text { da matéria-prima e a } \\
\text { solicitação dos pedidos de } \\
\text { venda. } \\
\text { Controle de qualidade não } \\
\text { formalizado. } \\
\text { Não há diversidade nos } \\
\text { produtos. }\end{array}$ & $\begin{array}{l}\text { Estratégia de produzir a } \\
\text { própria fruta, para reduzir } \\
\text { custos de transação. } \\
\text { Possui parcerias com } \\
\text { produtores, para a compra } \\
\text { de fruta. } \\
\text { Visita clientes para } \\
\text { identificar necessidades. } \\
\text { Preço e canal de } \\
\text { distribuição definidos de } \\
\text { acordo com o custo e com } \\
\text { a oferta e a procura pelos } \\
\text { produtos. }\end{array}$ \\
\hline
\end{tabular}

Revista Produção Online. Florianópolis, SC, v. 18, n. 1, p. 3-35, 2018. 


\section{CONSIDERAÇÕES FINAIS}

O objetivo deste estudo exploratório foi fazer um exercício de aplicação de um modelo que analisa a capacidade de inovação da empresa a partir de um olhar amplo e que defende que tal capacidade é constituída por rotinas presentes em diferentes áreas (de desenvolvimento, operação, gestão e comercialização) e essas são capazes de explicar como se dá a diferenciação da firma no mercado. O estudo foi realizado em duas firmas brasileiras atuantes em um segmento produtivo considerado de baixa intensidade tecnológica.

Entende-se que há relevância em registrar tal exercício na forma de estudo acadêmico no sentido da demonstração de como diferentes capacidades se comportam e influenciam o poder inovativo das firmas. A aplicação em empresas de baixa intensidade tecnológica ganha relevância considerando-se que o modelo analisado não enfoca a capacidade de inovação pelo indicador de gastos em P\&D, mas em capacidades diversas que são tão ou mais relevantes para a geração de inovações. Tal modelo, enquanto proposta de compreensão da capacidade de inovação da firma, é bastante explicativo para a realidade de empresas de países em desenvolvimento, cuja característica inovativa, em geral, refere-se mais à imitações do que há inovações disruptivas.

As conclusões apresentadas dividem-se em duas partes: resultados para as firmas investigadas e seus desdobramentos; e resultados relativos ao uso do modelo.

No que diz respeito aos resultados para as firmas investigadas, destaca-se:

1) foram identificas capacidades mínimas em cada uma das dimensões previstas no modelo usado, conforme premissa de que nenhuma capacidade é nula. Também foi possível identificar (com base na análise das respostas e no entendimento das empresas) que há uma capacidade, dentre as quatro, que se destaca. No caso da empresa SOL foi a capacidade de transação e no caso da empresa RENOVA foi a capacidade de operação.

2) a capacidade de desenvolvimento (aquela que é traduzida pela realização da inovação tecnológica) não se destacou nas atividades das duas empresas investigadas, como previsto, visto que se trata de baixa intensidade tecnológica. Tanto essa capacidade é menos relevante, que quando as duas empresas fizeram a 
classificação de suas capacidades, por ordem de importância, a colocaram em último lugar. Esse resultado aponta para o entendimento de que essa é uma realidade para empresas de baixa intensidade tecnológica, conforme já ponderado. Para reforçar, releva observar ainda que para Robertson e Smith (2008), setores de baixa intensidade têm oferecido pequenas variações de produtos essencialmente iguais, que mudam pouco ao longo do tempo. Além disso, alguns autores relacionam a inovação nesses setores com mudanças nos métodos de produção (Bell; Pavitt, 1995), com a aquisição de máquinas e equipamentos (Bell; Pavitt, 1995) e com o relacionamento e integração com os fornecedores (Hoveskog, 2011); e, por fim

3) o estudo reforça a necessidade de uma compreensão ampla a respeito do que é e como se gera a inovação na firma, com vistas a nortear estratégias públicas e privadas para o aumento da competitividade das empresas. Pode-se entender, a partir da realidade das duas empresas estudadas, que inovar significa se diferenciar (mesmo que pouco), gerar ganho de mercado (ainda que temporário), desenvolver novos produtos, processos e mercados (ainda que em nível incremental).

Em relação aos resultados relativos ao uso do modelo, apresenta-se a seguinte síntese:

1) o modelo das quatro dimensões da capacidade de inovação utilizado apresentou-se útil para investigar as características da geração de inovações pelas firmas estudadas, pois consegue captar os esforços diversos que as empresas realizam para obterem diferenciação no mercado, e não apenas os esforços de desenvolvimento tecnológico de modelos tradicionais mais difundidos. O uso de uma abordagem mais tradicional para analisar as empresas investigadas não captaria importantes rotinas e atividades que formam a capacidade de inovação das firmas investigadas;

2) a utilidade do modelo também é reconhecida quando aplicado a empresas de baixa intensidade tecnológica, onde, em geral, a centralidade da diferenciação competitiva dessas encontra-se em outras capacidades e não na capacidade de desenvolvimento (ou tecnológica);

3) o artigo apresenta o primeiro estudo que aplicou o modelo de Zawislak et al. (2012) em empresas agroindustriais. Neste ponto, acredita-se que há uma contribuição em relação às demais aplicações do modelo, que focaram em empresas 
industriais, conforme já mencionado e listado anteriormente. Isso reforça a relevância da lógica assumida pelo modelo: da diversidade de capacidades que compõem a 'meta-capacidade da inovação'.

Os resultados referentes ao modelo explicitados neste estudo certamente precisam ser confirmados por outros estudos, devido ao fato da limitação intrínseca de um desenho de pesquisa exploratória realizada em duas empresas. Além disso, entende-se como fundamental explorar melhor a percepção presente no modelo de que uma das quatro capacidades deve-se destacar para explicar o elemento norteador da inovação da firma. Essa questão foi apresentada como um resultado da investigação para as firmas aqui estudadas devido à resposta direta delas referente a essa questão. Contudo, registra-se a complexidade de se lidar com uma capacidade de destaque, visto que as rotinas que caracterizam as capacidades podem se sobrepor em alguns momentos, não explicitando claramente qual capacidade se sobressai. Além disso, também se questiona: 'não seria possível considerar mais de uma das quatro capacidades previstas para guiar a inovação da firma'? Aponta-se, assim, a necessidade de discutir e aperfeiçoar alguns aspectos do modelo, bem como aplicá-lo em mais estudos que se referem a setores de baixa intensidade tecnológica.

\section{REFERÊNCIAS}

ARCHIBUGI, D.; PIANTA, M. Measuring technological change through patents and innovation surveys. Technovation, v. 16, n. 9, p. 451-519, 1996.

https://doi.org/10.1016/0166-4972(96)00031-4

BARNARD, C. The functions of the executive. Harvard University Press, Cambridge. First published in 1938; 1966.

BELL, M.; PAVITT, K. The development of technological capabilities. Trade, technology and international competitiveness, v. 22, p. 69-101, 1995.

CHANDLER, Alfred D., Jr. The visible hand. Cambridge, Mass. and London, England: The Belknap Press of Harvard University Press, 1977.

CHANDLER, Alfred D., Jr. Scale and Scope. Cambridge, MA. The Belknap Press of Harvard University Press, 1990.

COASE, R. The nature of the firm. Economica, v. 4, n. 16, p. 386-405, 1937.

https://doi.org/10.2307/2626876 
COOMBS, J. E., \& BIERLY, P. E. Measuring technological capability and performance. R\&D Management, v. 36, n. 4, p. 421-438, 2006. https://doi.org/10.1111/j.1467-

9310.2006.00444.x

Dosi, G. Sources, procedures, and microeconomic effects of innovation. Journal of Economic Literature, p. 1120-1171, 1988.

EMATER/RS. Visita à unidade localizada em Vacaria-RS, para coleta de dados em 14 de junho de 2012.

FELLOWS, P.J. Tecnologia do processamento de alimentos: princípios e prática. 2.ed. Porto Alegre, RS: Artmed, 2006.

FIGUEIREDO, P. Gestão da inovação: conceitos, métricas e experiências de empresas no Brasil. Rio de Janeiro: LTC, 2009.

GARCÍA-MUIÑA, F.; NAVAS-LÓPEZ, J. Explaining and measuring success in new business: the effect of technological capabilities on firm results. Technovation, v. 27, p. 30-46, 2007. https://doi.org/10.1016/j.technovation.2006.04.004

GIANEZINI, Miguelangelo. ALVES, Admar Bezerra. TECHEMAYER, César Augustus. Révillion, Jean Philippe Palma. Diferenciação de produto e inovação na indústria agroalimentar: a inserção de alimentos funcionais no Brasil. RACE, v. 11, n. 1, Edição Especial Agronegócios, p. 9-26, jan./jun. 2012

GUAN, J., \& MA, N. Innovative capability and export performance of Chinese firms. Technovation, v. 23, n. 9, p. 737-747, 2003. https://doi.org/10.1016/s01664972(02)00013-5

HALL, L. A.; BAGCHI-SEN, S. A study of R\&D, innovation, and business performance in the Canadian biotechnology industry. Technovation, v. 22, n. 4, p. 231-244, 2002.

https://doi.org/10.1016/s0166-4972(01)00016-5

HANSEN, T., \& WINTHER, L. Innovation, regional development and relations between highand low-tech industries. European Urban and Regional Studies,v. 18, n. 3, p. 321-339, 2011. https://doi.org/10.1177/0969776411403990

HAYES, R. H., PISANO, G. P. Beyond world-class: The new manufacturing strategy. Harvard Business Review, p. 77-86, 1994.

HIRSCH-KREINSEN, H., HAHN, K. \& JACOBSON, D. The low-tech issue. In: HIRSCHKREINSEN, H., \& JACOBSON, D. (Eds.). Innovation in low-tech firms and industries. Edward Elgar Publishing, p. 3-32, 2008.

HOVESKOG, M. Innovation-related activities in a low-tech industry: a study of electroplating and surface treatment industry in Sweden. In: HALMSTAD, HOGSKOLAN \& HALMSTAD. Research on technology, innovation and marketing management, 2011.

IAMMARINO, S.; PADILLA-PÉREZ, R.; VON TUNZELMANN, N. Technological capabilities and Global-Local Interactions: the Electronics industry in two Mexican regions. World Development, v. 36, n. 10, p. 1980-2003, 2008. https://doi.org/10.1016/i.worlddev.2007.10.022 
JENSEN, M.B., JOHNSON, B., LORENZ, E. y B. LUNDVALL. Forms of knolwedge and modes of innovation. Research Policy, v. 36, n. 5, p.680-693, 2007.

https://doi.org/10.1016/j.respol.2007.01.006

JIN, J.; VON ZEDTWITZ, M. Technological capability development in China's mobile phone industry. Technovation, v. 28, n. 6, p. 327-334, 2008.

https://doi.org/10.1016/j.technovation.2007.06.003

KIM, L. Building technological capability for industrialization: analytical frameworks and Korea's experience. Industrial and Corporate Change, v. 8, n. 1, p. 11-136, 1999. https://doi.org/10.1093/icc/8.1.111

LALL, S. Technological capabilities and industrialization. World development, v. 20, n. 2, p. 165-186, 1992. https://doi.org/10.1016/0305-750x(92)90097-f

LANGLOIS, R.N., FOSS, N. Capabilities and governance: the rebirth production in the theory of economic organization. Kyklos, v. 52, n. 2, p. 201-218, 1999.

https://doi.org/10.1111/1467-6435.00081

LOURDES, C.; FIGUEIREDO, P.N. Mensuração de capacidades tecnológicas inovadoras em empresas de economias emergentes: méritos limitações e complementaridades de abordagens existentes. Revista Produção Online, v. 9, n.1, p. 95-12, março 2009. https://doi.org/10.14488/1676-1901.v9i1.213

MADANMOHAN, T. R., KUMAR, U., \& KUMAR, V. Import-led technological capability: A comparative analysis of Indian and Indonesian manufacturing firms. Technovation, v. 24, n. 12, p. 979-993, 2004. https://doi.org/10.1016/s0166-4972(03)00030-0

MADHOK, A. The organization of economic activity: transaction costs, firm capabilities and the nature of governance. Organization Science, v. 7, n. 5, p. 577-590, 1996.

https://doi.org/10.1287/orsc. 7.5 .577

MALERBA, F. Sectoral systems of innovation and production. Research Policy, v. 31, n. 2, p. 247-264, 2002. https://doi.org/10.1016/s0048-7333(01)00139-1

MALERBA, F., \& ORSENIGO, L. Technological regimes and sectoral patterns of innovative activities. Industrial and Corporate Change, v. 6, n. 1, p. 83-118, 1997.

https://doi.org/10.1093/icc/6.1.83

MINTZBERG, H. The Nature of Managerial Work. Harper \& Row, New York, 1973.

OECD. Technology intensity definition. ISIC rev. 3, 2011. Retrieved from www.oecd.org/std/its/41419823.ppt.

OECD. Reviewing the nomenclature for high-technology trade: the sectoral approach. 2014. Retrieved from www.oecd.org/std/its/41419823.ppt

PAGOT, Eduardo. Direcionadores de valor críticos na cadeia produtiva de pequenas frutas em Vacaria/RS. Monografia (Graduação) - UNISINOS, 2010. 
PANDA, H.; RAMANATHAN, K. Technological capability assessment of a firm in the electricity sector. Technovation, v. 16, n. 10, p. 561-588, 1996.

https://doi.org/10.1016/s0166-4972(97)82896-9

PAVITT, K. Sectoral patterns of technical change: towards a taxonomy and theory.

Research Policy, v. 13, n. 6, p. 343-373, 1984. https://doi.org/10.1016/0048-

7333(84)90018-0

PENG, D. X., SCHROEDER, R. G., SHAH, R. Linking routines to operations capabilities: A new perspective. Journal of Operations Management, v. 26, n. 6, p. 730-748, 2008. https://doi.org/10.1016/j.jom.2007.11.001

PENROSE, E. The theory of the growth of the firm. Oxford University Press, New York, 1959.

REICHERT, F.M., BELTRAME, R.S., CORSO, K.B., TREVISAN, M. \& ZAWISLAK, P.A. Technological capability's predictor variables. Journal of Technology Management and Innovation, v. 5, n. 1, p. 14-25, 2011. https://doi.org/10.4067/s0718-27242011000100002

REICHERT, F. M., ZAWISLAK, P. A. Technological capability and firm performance. Journal of technology management \& innovation, v. 9, n. 4, p. 20-35, 2014.

https://doi.org/10.4067/s0718-27242014000400002

REICHERT, F. M.; CAMBOIM, G. F.; ZAWISLAK, P.A. Capacidades e trajetórias de inovação de empresas brasileiras. Revista de Administração Mackenzie (Online), v. 16, p. 161-194, 2015. https://doi.org/10.1590/1678-69712015/administracao.v16n5p161-194

RÉVILLION, Jean Philippe Palma; PADULA, Antônio Domingos; FEDERIZZI, Luiz Carlos; MARTINELLI, Orlando Junior; MANGEMATIN, Vicent. Estudo do processo de inovação tecnológica no setor agroindustrial - estudos de caso na cadeia produtiva de leite fluido no sistema setorial de inovação da França. Revista de Administração Contemporânea, v. 8, n. 3, Jul./Set. 2004: 75-98. https://doi.org/10.1590/s1415-65552004000300005

ROBERTSON, P.L. \& SMITH, K. Distributed knowledge bases in low- and mediumtechnology industries. In: HIRSCH-KREINSEN, H., \& JACOBSON, D. (Eds.). Innovation in low-tech firms and industries. Edward Elgar Publishing, p. 93-117, 2008.

RUFFONI, Janaína; ZAWISLAK, Paulo A. REICHERT, Fernanda M; PUFAL, Nathália; ROSSI, Greice de. Innovation capabilities arrangement: an analysis for the footwear productive sector. Working Paper, n. 009; Escola de Gestão e Negócios, Mestrado em Economia, UNISINOS, janeiro de 2015.

SOLOW, R. M. Technical change and the aggregate production function. The review of Economics and Statistics, v. 39, n. 3, p. 312-320, 1957. https://doi.org/10.2307/1926047

TELLO-GAMARRA, J. \& ZAWISLAK, P. A. Transactional capability: innovation's missing link. Journal of Economics, Finance and Administrative Science, v. 18, n. 34, p. 2-8, 2013. https://doi.org/10.1016/s2077-1886(13)70017-9

TSAI, K. H. The impact of technological capability on firm performance in Taiwan's electronics industry. The Journal of High Technology Management Research, v. 15, n. 2, p. 183-195, 2004. https://doi.org/10.1016/i.hitech.2004.03.002 
VALLADARES, P. S. D.; VASCONCELLOS, M. A.; SERIO, L. C. Capacidade de inovação: revisão sistemática da literatura. Revista de Administração Contemporânea, v. 18, n. 5, p. 598, 2014. https://doi.org/10.1590/1982-7849rac20141210

VAN HEMERT, P.; NIJKAMP, P.; MASUREL, E. From innovation to commercialization through networks and agglomerations: analysis of sources of innovation, innovation capabilities and performance of Dutch SMEs. The Annals of Regional Science, v. 50, n. 2, p. 425-452, 2013. https://doi.org/10.1007/s00168-012-0509-1

VON TUNZELMANN, N., ACHA, V. Innovation in "low-tech" industries. In FAGERBERG, J., MOWERY, D. C., \& NELSON, R. R. (Eds.). The Oxford Handbook of Innovation. New York: Oxford, p. 407-432, 2005.

WANG, C. H., LU, I. Y., CHEN, C. B. Evaluating firms technological innvovation capability under uncertainty. Technovation, v. 28, n. 6, p. 349-363, 2008.

https://doi.org/10.1016/j.technovation.2007.10.007

WILLIAMSON, O. The economic institutions of capitalism. Free Press, New York, 1985. $450 \mathrm{p}$.

WILLIAMSON, O. E. Strategy research: governance and competence perspectives.

Strategic Management Journal, v. 20, n. 12, p. 1087-1108, 1999.

https://doi.org/10.1002/(sici)1097-0266(199912)20:12\%3C1087::aid-smi71\%3E3.0.co;2-z

WILLIAMSON, O. E. The theory of the firm as governance structure: from choice to contract. Journal of Economic Perspectives, v.16, n. 3, p. 171-195, 2002.

https://doi.org/10.1257/089533002760278776

YAM, R., GUAN, J. C., PUN, K. F., \& TANG, E. P. An audit of technological innovation capabilities in Chinese firms: some empirical findings in Beijing, China. Research Policy, v. 33, n. 8, p. 1123-1140, 2004. https://doi.org/10.1016/j.respol.2004.05.004

ZAWISLAK, P. A., ALVES, A. C., TELLO-GAMARRA, J., BARBIEUX, D. \& REICHERT, F. M. Innovation Capability: From Technology Development to Transaction Capability. Journal of Technology Management \& Innovation, v. 7, n. 2, p. 14-27, 2012.

https://doi.org/10.4067/s0718-27242012000200002

ZAWISLAK, Paulo Antônio et al. The innovation capabilities: a content analysis in Brazilian cases. Revista IAMOT, 2012b

ZAWISLAK, P. A., ALVES, A. C., TELLO-GAMARRA, J., BARBIEUX, D. \& REICHERT, F. M. Influences of the Internal Capabilities of Firms on their Innovation Performance: A Case Study Investigation in Brazil. International Journal of Management, v. 30, 2013(a).

ZAWISLAK, P. A., ZEN, A. C., FRACASSO, E. M., REICHERT, F. M. \& PUFAL, N. A. Types of innovation in low-technology firms of emerging markets: an empirical study in Brazilian Industry. Revista de Administração e Inovação, v. 10, n. 1, p. 212-231, 2013(b). https://doi.org/10.5773/rai.v1i1.1105

ZAWISLAK, P. A.; TELLO-GAMARRA, J.; ALVES, A. C.; BARBIEUX, D; REICHERT, F. M. The different innovation capabilities of the firm: further remarks upon the Brazilian 
experience. Journal of Innovation Economics, v. 13, n.1, p. 129-150, 2014. https://doi.org/10.3917/jie.013.0129

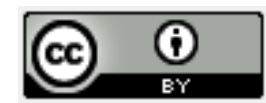

Artigo recebido em 23/06/2016 e aceito para publicação em 12/12/2017

DOI: http://dx.doi.org/10.14488/1676-1901.v18i1.2506 